IFPMA, said the MMV is "the start of a new era of partnership between the research-based pharmaceutical industry and WHO to bring about real improvements in world health". But not everyone is so happy. Médecins sans Frontières (MSF), the Nobel Prize-winning international relief organization, has expressed "pessimism" that the MMV will achieve its objectives.

Bernard Pécoul, head of a new initiative at MSF to

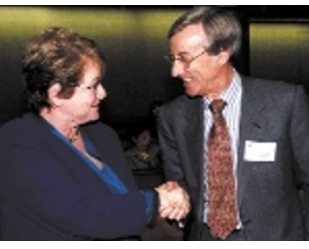

Gro Harlem Brundtland and Richard Sykes, CEO of Glaxo Wellcome. campaign for better access

to treatment drugs in developing nations, says that the sum the venture expects to spend on each new drug- $\$ 150$ to $\$ 180$ million-is higher than necessary, even though it is well below the $\$ 500$ million often quoted as necessary by the companies themselves. The Walter Reed Army Institute of Research, Washington DC, credited with developing antimalarial drugs such as mefloquine and halofantrine, has developed drugs for $\$ 30$ million, he says.

Pécoul also believes that the MMV has too few links with people in endemic countries or pharmaceutical companies in some of the emerging Asian nations such as India, Malaysia and Thailand. "I was at the launch and I was surprised by the absence of [these companies] who have some ability to develop drugs," he says. Nevertheless, he stressed that the idea of the MMV overall was welcome. "We should not be only negative, because we need these kind of initiatives," he warned.

A fiercer critic is former-immunologist-turned-lawyer, Amir Attaran, who runs a small organization called The Malaria Project in Washington DC, under the umbrella of the well-known public-interest advocate Ralph Nader. Attaran circulated a critique of the MMV before the launch arguing that although companies will contribute expertise and facilities to the scheme, they will get valuable patent rights as a result, without any obligation to sell drugs at prices that developing countries could afford. In essence, Attaran argues, the venture gives the pharmaceutical companies a blank check from the public sector.

Robert Ridley, acting chief executive officer at the MMV, rejects these claims. "At the outset of drug discovery projects are still many years away from delivering a registered drug, and it is not possible to [determine] what the final price of the drug is going to be," he says, adding that the MMV projects selected so far are focused on compounds that are inexpensive to manufacture. Ridley also doubts that public agencies can develop drugs more cheaply. The MMV "is not a piecemeal approach and it makes no excuses about trying to obtain appropriate funds to do the job professionally and do it well."

The MMV's launch is the latest in a flurry of international activity designed to reduce the yearly toll of 1 million deaths from malaria. The MMV joins the three-year-old Multilateral Initiative on Malaria (MIM), an alliance of research organizations and their paymasters which aims to coordinate scientific activity on malaria and build up research capacity in endemic areas.

The MIM has already achieved some of its goals such as the establishment of a repository for standardized research reagents. Both the MIM and MMV fall under the umbrella of a third partnership, Roll Back Malaria, set up last year by Brundtland with other UN agencies to halve malaria deaths by 2010 . Days before the launch of the MMV, a group of 12 Japanese pharmaceutical companies and the Japanese government announced that they would join WHO in a fourth, complementary partnership for screening molecules for antimalarial activity.

Phyllida Brown, London

\section{Japan hosts its first xenotransplantation conference}

Japan has demonstrated its interest in animal-to-human transplants by hosting its first international meeting to discuss the technique. But as expected from a country that is only just coming to terms with the process of human organ transplantation, the $5^{\text {th }}$ Meeting of the International Xenotransplantation Association in Nagoya revealed the lack of a regulatory framework for potential xenotransplantation trials.

According to Kikuo Nomoto, a professor in the Department of Immunology at the University of Kyushu, the Japanese Ministry of Health and Welfare (MHW) has established a blueprint for a regulatory framework for xenotransplantation studies that is compatible with the regulatory approaches proposed in Europe and the US. This would include the creation of a surveillance agency to monitor transplant recipients and their closest contacts for the transmission of xenotic viruses. But such regulation looks unlikely to be implemented in the near future, and in the meantime clinical trials with xeno- transplants are likely take place in a "dangerous regulatory void," says Jiro Nudeshima, a health policy analyst at the Mitsubishi Kasei Institute of Life Sciences.

Nudeshima points out that according to Japanese legislation, trials that are not related to new pharmaceutical products are not subject to oversight by the Health Ministry. "At present, there are no real guidelines for clinical trials with xenotransplantation, neither has the Ministry any real mechanism to monitor such trials," he says.

Researchers who are pushing ahead with the technique are encountering this vacuum. Takashi Omoto, a neurosurgeon at Okayama University, has prepared a protocol for clinical trials of xenografts of ratderived islet cells to treat Parkinson disease. Omoto consulted with both the Education Ministry and the MHW on the issue, and was advised to submit his protocol to the university's Ethics Committee, which approved it this March.
"Neither the Education Ministry nor the MHW seemed to be prepared to take any responsibility for this," says Omoto.

Only a handful of human organ transplants have been performed in Japan since a new law regulating organ donation went into force just over a year ago, and almost ten years after a MHW expert panel on brain death ("Noshi rincho") delivered its report on the issue. Hiroshi Takagi, director of the JR Tokai General Hospital in Nagoya, and head of the local organization committee for the xenotransplantation meeting, argues that "it may take another decade before the practice of organ transplants becomes accepted" and that "Japan should pursue research on alternatives like xenografts more aggressively."

But Nomoto, a prime mover behind the new human transplant law, argues that is simply too early to push ahead with xenotransplanation. "We have to overcome the mental barriers towards organ transplants in this country before we can deal with any other issue."

Robert Triendl, Nagoya 